\title{
Expanding the moral circle: farmed fish as objects of moral concern
}

\author{
Vonne Lund $^{1, *}$, Cecilie M. Mejdell ${ }^{1}$, Helena Röcklinsberg ${ }^{2}{ }^{2}$ Ray Anthony ${ }^{3}$, Tore Håstein ${ }^{1}$ \\ ${ }^{1}$ National Veterinary Institute, PO Box 8156 Dep., 0033 Oslo, Norway \\ ${ }^{2}$ Centre for Theology and Religious Studies, Lund University, Allhelgona Kyrkogata 8, 22362 Lund, Sweden \\ ${ }^{3}$ Department of Philosophy, University of Alaska Anchorage, 3211 Providence Drive, Alaska 99508, USA
}

\begin{abstract}
Until recently fish welfare attracted little attention, but international and national legislation and standards of fish welfare are now emerging and an overview of these developments is presented in this study. Whereas animal welfare legislation is based on public morality, animal ethics does not automatically accept public morality as normative and elaborates arguments regarding the way humans should treat animals (referred to as moral standards). In this study we present the most common animal ethics theories. For most of these, sentience is considered a demarcation line for moral concern: if an animal is sentient, then it should be included in the moral circle, i.e. receive moral consideration in its own right and some basic welfare should be ensured. As for fish, research has revealed that the sensory system of teleosts can detect noxious stimuli, and that some kind of phenomenal consciousness, allowing the fish to feel pain, seems to be present. This raises the ethical question as to how much evidence we need in order to act on such indications of fish sentience. A simple risk analysis shows that the probability that fishes can feel pain is not negligible and that if they do indeed experience pain the consequences in terms of the number of suffering individuals are great. We conclude that farmed fish should be given the benefit of the doubt and we should make efforts that their welfare needs are met as well as possible. Finally, the way forward is briefly discussed: efforts must be made to understand what fish welfare means in practical fish farming. This will involve the development of research and education, greater accountability and transparency, compliance with and control of policies, and quality assurance schemes.
\end{abstract}

KEY WORDS: Fish welfare $\cdot$ Animal welfare $\cdot$ Fish sentience $\cdot$ Animal ethics $\cdot$ Moral circle $\cdot$ Fish welfare legislation · Aquaculture

- Resale or republication not permitted without written consent of the publisher

\section{INTRODUCTION}

In Western culture there is a general agreement that at least some animals are entitled to certain moral respect and animal welfare considerations. More often than not, public morality is reflected in law or policy, and this also applies to animal welfare legislation. The first animal welfare legislation was established in England as early as 1822, and the comprehensive English 'Cruelty to Animals Act' was passed in 1876. Almost a hundred years later, in 1964, the Council of Europe stated that 'the humane treatment of animals is one of the hallmarks of Western civilization', and in the 1997 Treaty of Amsterdam, the European Union (EU) acknowledged that 'Member states shall pay full regard to the welfare of animals'. While some animals receive some measure of legal protection, there is still widespread disagreement and public debate on the question of which categories of animals should be afforded similar entitlements.

Questions related to whether or not animals are moral objects worthy of human consideration for their own sake are ethical questions. Discussions of these issues need to be based on scientific information regarding the capacities of animals and what contributes to or impairs their welfare. Normative ethics deals with establishing moral standards for what is right and good in relation to human actions. Animal ethics discusses the moral guidelines for the relationship between humans and animals. 'Fish ethics', then, deals with 
what human beings owe to fish. Moral respect and legal protection for animals, including fish, often translate into how best to promote or protect their quality of life or welfare.

In animal ethics, much of the attention in the past centred on the capacities of animals, more specifically on whether a species possesses certain mental qualities (most commonly the ability to suffer) to afford them entry into the moral community. In the case of fish, however, the ethical focus so far has been on species preservation, concerns related to over-fishing, pollution from fish farming etc., that is, to environmentally related issues. As the public is exposed to new scientific findings and as the animal issue gains more public currency, the welfare of fish as individuals has become an issue in its own right. For example, as new knowledge regarding fish capacities permeates into public consciousness, we can expect changing attitudes and values, and thus laws and policies in favour of more measures to protect or promote fish welfare. For terrestrial animals, such a process has been going on for a long time and has resulted in new or revised animal welfare legislation in the EU and many other countries. For fish, the process has just started with the emergence of more interest in the ethology and 'mental lives' of the animals by the research community. In the following we recount some interesting developments in fish welfare.

The Holmenkollen Guidelines (Sundli 1999), adopted in 1998, were among the first international protocols suggesting that ethical principles ensuring health and welfare of fish, including humane slaughter, should govern the aquaculture industry. The World Organization for Animal Health (OIE) has identified animal welfare as a priority area in its Strategic Plan (2001-2005). Fish welfare is also included in this mandate. Priority is given to developing animal welfare standards for agriculture as well as for aquaculture. These standards will be incorporated in the OIE Terrestrial and Aquatic Animal Health Codes (Håstein et al. 2005) which influence the World Trade Organization (WTO) rules for international trade with live animals and animal products. Introduction to guidelines for animal welfare and guidelines for the transport and slaughter of terrestrial animals were adopted in 2006, and similar guidelines for fish have been drafted by the OIE Working Group on Animal Welfare (AWWG) and the OIE Aquatic Animal Health Standards Commission (AAHSC). In 2006, these draft guidelines were sent for hearing to the OIE member countries; however, agreement has so far not been reached regarding their implementation.

In 2005, the Council of Europe passed recommendations for farmed fish under the Convention for the protection of animals for farming purposes (www.coe.int/t/e/legal_affairs/legal_co-operation/
biological_safety,_use_of_animals/farming/Rec \%20fish\%20E.asp\#TopOfPage). In 2004, the European Food Safety Authority (EFSA) issued scientific opinions considering transport and stunning/killing of farmed fish (Opinion adopted by the AHAW Panel related to the welfare of animals during transport, Question N EFSA-Q-2003-094; www.efsa.europa.eu/ science/ahaw/ahaw_opinions/424_en.html and Opinion of the Scientific Panel on Animal Health and Welfare on a request from the Commission related to welfare aspects of the main systems of stunning and killing the main commercial species of animals, Question No. EFSA-Q-2003-093; www.efsa.europa.eu/ science/ahaw/ahaw_opinions/495_en.html). Following this, the EU passed a regulation regarding the transport of vertebrates, including fish, which came into force in January 2007. At the request of the European Commission, in 2006 EFSA started work to issue a scientific opinion concerning animal welfare aspects of husbandry systems for farmed fish, including Atlantic salmon Salmo salar, sea bass Dicentrarchus labrax, gilthead sea bream Sparus aurata, rainbow trout Oncorhynchus mykiss, carp Cyprinus carpio and European eel Anguilla anguilla.

Fish welfare is also considered in some national animal welfare legislation and recommendations, as evidenced in the New Zealand Animal Welfare Act (1999), the Australian Capital Territory Animal Welfare Act (1992) and the Queensland Government Animal Care and Protection Act (2001). In Norway, fish have explicitly been included in the Animal Welfare Act since 1974, and a new act (expected in 2007) will give fish protection on a level similar to other vertebrates. The countries mentioned also include decapods and cephalopods in their welfare legislation. The UK include common octopus Octopus vulgaris in the Animals (Scientific Purposes) Act (1986).

In this paper we apply animal ethics theories to the issue of fish welfare, drawing on science (in particular the science dealing with sentience) for support, and present some conclusions as to how this ethical reasoning may be implemented in practical fish farming. The paper begins by a philosophical discussion of how animals have gained entry into the moral circle, that is, gained moral consideration. These philosophical perspectives reflect and influence our attitudes about what is owed to animals and warrant change in human behaviour, policy and practice. We explore the role sentience has played in propelling vertebrates such as fish into the moral community, and, hence, also consider some of the significant moral pronouncements or theories regarding animal ethics. Based on a review of the scientific literature, we argue that since fish sentience cannot be ruled out, the moral consequence is that fish welfare should be given serious ethical con- 
sideration. We briefly discuss how the concept of 'fish welfare' may be interpreted and suggest some steps needed to implement welfare standards in aquaculture.

Throughout the paper we primarily consider teleost fish, since most farmed species belong to this group. The ethical discussion regarding a sentient animal's right to life falls beyond the scope of this article (see Röcklinsberg 2001, Lund \& Olsson 2006).

\section{HOW ANIMALS MAKE IT INTO THE MORAL CIRCLE}

The contemporary animal protection movement has for approximately the last half century been arguing for expanding the moral community. To be a member of the moral community or moral circle is to be a being whose interests are given serious moral consideration for its own sake (Singer 1981). Membership in the moral community depends on whether the being concerned possesses certain characteristics or traits that we consider to be morally relevant. Focussing on these traits, we present some of the most influential animal ethics theories and their arguments as to why animals should be included in the moral circle.

While during the early history of mankind only the family group or clan were included in the moral circle, the circle eventually expanded to include all of humanity, which put an end to slavery and resulted in the UN Declaration of Human Rights. Today, the World Society for the Protection of Animals (WSPA) is campaigning for a 'Universal Declaration on Animal Welfare' to be approved by the UN. Sentience, i.e. the capacity of having sensations such as pain and pleasure, is in Western society commonly considered an important determinant and perhaps the single most important criteria for moral status of animals. The idea that suffering capacity is morally relevant regardless of species was first launched among western philosophers during the 18th century (Bentham 1789). Although different schools of ethics have spelled out different types of arguments why animals should (or should not) be morally considered, most current animal ethicists use sentience as a demarcation line for ascribing direct moral consideration.

Utilitarian philosophy prescribes the quantitative maximization of good consequences for a population. Peter Singer (1990), a utilitarian philosopher and one of the most well-known animal ethicists, has championed the view that sentience rather than species should decide whether individuals are to be included in the moral circle. According to Singer, if non-human animals are sentient, their welfare must be included along with the welfare of other sentient beings, humans and nonhumans alike when evaluating the consequences of any production practice. That is to say, from a utilitarian perspective humans have a responsibility to balance the burdens and benefits of all the sentient individuals (humans and otherwise) affected by a course of action. Thus, if fish are sentient, humans would have a responsibility to at least consider their welfare (or other interests) seriously.

Another influential philosopher, Mary Midgley, argues from an ethics of care approach (Midgley 1983). She sees our moral responsibilities as derivative of our relationships with others. In Midgley's view, our moral communities are mixed in nature, such that they also include animals. This sense of community or connectedness, captured by our shared evolutionary backgrounds and close human-animal relationships, serves as the basis of our ethical obligations to animals. For example, the domestication relationship we have with farmed fish today entails having a responsibility to care for their needs. Others have extended the idea and argued that the human-animal relationship in farming could be formulated according to the idea of a tentative contract (Larrère \& Larrère 2000, Lund et al. 2004). This can enjoin us to share the wealth created in aquaculture with all those (sentient) beings contributing to it, and care for the welfare of the individual animal, protecting the fish from unnecessary exploitation (similar to human co-workers on a farm who should not be exploited).

Tom Regan, an animal rights philosopher, argues that certain non-human animals also have inherent value and are the bearers of moral rights. The animals to be included in the moral circle are those that are 'subject-of-a-life', that is, beings with a complex mental life, including perception, desire, belief, memory, intention, and a sense of the future-in other words, sentient beings. The basic right of any 'subject-of-alife' is the right never to be treated merely as a means to the ends of others (Regan 1983).

Bernard Rollin is also committed to a variant of the 'rights-based' stance, recognizing that sentient beings should have certain rights in terms of welfare and also emphasizing a particular kind of care ethics or husbandry (Rollin 1995). While sentience puts the animal in the moral circle, what is distinctive about Rollin's view is that animal welfare follows from their distinctive telos or 'natures' (explained as 'the piggishness of a pig'). Telos are the central defining properties which capture the good of the being in question and form the basis for moral respect. An important characteristic of the telos would be the animal's species-specific behaviour. The idea of telos is borrowed from Aristotle and applied by Rollin to animals. In terms of responsibilities to animals, Rollin argues that regulations and standards should accommodate the expression or fulfillment of evolutionarily imprinted natural behaviours or 
lives, respectively, and that technological fixes and management practices that attempt to squeeze 'square pegs into round holes,' should be revisited if not abandoned. Production systems which go against animals' telos should be minimized or abolished.

In contrast to the above-mentioned views, other scholars have sought to keep animals from being members of the moral community in their own right. Animals, they claim, are not members of the moral community because they are not moral agents (Kant 1980), they do not have human rationality (Descartes 1988, Kant 1980, Aquinas 1947), or they do not possess language (Frey 1980). A case in point is the 18th century philosopher Immanuel Kant. According to Kant's duty ethics, animals cannot be objects of direct moral concern since they are not rational. Nevertheless, we should not harm or kill them without a good reason since ill treatment of animals may result in the development of callousness in human beings. Kant did not stress the loss of empathy as a morally relevant trait, but he inadvertently considers the capacity for sentience as the very basis for animal protection and care, since his argument is based on the human capacity to feel empathy with other species (Wolf 1992).

For the purposes of the present study we devote our attention to the criteria of sentience. We contend that sentience is the least common denominator for inclusion in the moral community. Entities that do not possess sentience cannot be said to have moral interests or a welfare; that is, things cannot be said to go better or worse for them without this property (e.g. since a rock cannot feel pain, it has no welfare, but since a human child can feel pain or is sentient, s/he does). Our claim that the welfare of fish should be given serious moral consideration is dependent on their possession of the morally relevant similarity of sentience. The general line of reasoning we are advancing here is as follows: (1) If a being is sentient, then it deserves serious moral consideration. (2) Fish are likely to be sentient. (3) Therefore, fish deserve serious moral consideration.

While the first premise expresses normative ethics, the second premise depends on empirical evidence, which we will briefly discuss in the following section. Arguments and judgments regarding fish sentience are usually based on physiological or ethological observations. Substantial lack of scientific knowledge and the fact that there are some 30000 teleost species, comprising an extremely diverse group of fish, make it difficult to draw general conclusions about 'fish capacities'. Still, there is evidence suggesting that fish sentience cannot be ruled out, as discussed in the following section. Also, absence of scientific evidence should not be interpreted as evidence of the absence of sentience. The aim of this paper is not to give a complete account of relevant scientific arguments for fish sen- tience, but to point to some facts and arguments supporting the theory that at least some fish species are sentient.

\section{PHYSIOLOGICAL INDICATIONS OF SENTIENCE IN FISHES}

Based on similarities in the central nervous systems of different taxa and behavioural reactions to potentially painful stimuli, an increasing number of researchers have suggested that some form of pain perception, similar to what is present in mammals, may be present in bony fish (teleosts) (e.g. Sneddon et al. 2003a, Chandroo et al. 2004a, Sohlberg et al. 2004, Huntingford et al. 2006, Børresen in press). Pain is the unpleasant sensory and emotional experience associated with actual or potential tissue damage (www. iasp-pain.org/terms-p.html\#Nociceptor). Pain is thus distinguished from nociception, which is the physiological activity induced in the nociceptor and nociceptive pathways (leading to the central nervous system) by a noxious stimulus.

Fish have many neuroanatomical similarities with other vertebrates as regards nociceptors, nerve fibres, and neurophysiology (e.g. The Avian Brain Nomenclature Consortium 2005, Sneddon 2002, Sneddon et al. 2003a, Lieberman 2006). Most neuropeptides, neurotransmittors and opioid receptors involved in nociception and pain modulation in mammals are also found in fish (see review by Huntington et al. 2006).

The main argument used against pain perception in fish is that the fish brain lacks a neocortex (Rose 2002), since this is involved in the human perception of pain (Bermond 1997). It is commonly assumed that a species' cognitive potential and degree of consciousness correlates positively with the relative size of the prefrontal cortical region (e.g. Fuster 1980). However, current research provides no indication of any distinct brain structure acting as a unitary neural substrate of subjective consciousness (e.g. Crick \& Koch 1990). For example, the human 'record' of $33 \%$ of the neocortical area occupied by the prefrontal cortical area, is well surpassed by an egg-laying mammal (the echidna, Tachyglossus aculeatus), for which the corresponding figure is $50 \%$ (e.g. Divac et al. 1987). Also, birds lack a neocortex as a distinct brain area but they show convincing signs of pain, for example, selecting feed with pain killers under circumstances that would be experienced as painful by humans (Gentle 1992, Danbury et al. 2000). The posterodorsolateral neostriatum functions in pigeons have been shown to be equivalent to the prefrontal cortex of mammals (Mogensen \& Divac 1982). Moreover, the significance of the neocortex for emotions in humans is disputed. New scientific devel- 
opments using techniques such as functional magnetic resonance imaging (fMRI) are modifying or altering existing models, showing a level of complexity not previously expected, and involving brain areas that were not previously considered to be part of the emotional pathway (Kalisch et al. 2006). The classical view on telencephalic evolution and the function of different brain areas has been challenged, and it has been suggested that the telencephalon is organized into 3 developmentally distinct domains (the pallial, striatal and pallidal domains) that are homologous in all vertebrates, including fish. A new nomenclature for brain anatomy has thus been proposed which better reflects brain functions (The Avian Brain Nomenclature Consortium 2005). Another explanation of the ability to experience pain in the absence of a neocortex is based on the argument of analogy. According to this argument, species that separated early in evolution may have developed different types of brain structures to solve similar socio-ecological challenges, an example of so called convergent mental evolution. Thus, sentience may evolve in the absence of a prefrontal cortex (Emery \& Clayton 2004). The fact that fish species have a much smaller relative brain size compared to humans does not necessarily indicate non-sentience. It has been suggested that relatively simple feelings like pain and hunger may not need extensive brain processing, in contrast to more complex feelings like guilt and jealousy (Broom 1998).

\section{BEHAVIOUR, COGNITION AND CONSCIOUSNESS IN FISHES}

Consciousness in the sense of being awake, not asleep or unconscious (i.e. primary or phenomenal consciousness), is necessary to be aware of feelings, i.e. for sentience. Whether and how a moral subject can be harmed depends on whether or not his/her phenomenal experiences are conscious. Thus, there has been a recurrent debate as to whether nociceptive stimuli are consciously perceived by fish, or if their reactions are more or less mechanical responses to stimuli. To produce indisputable proof of consciousness is difficult, and whether it is possible at all in animals other than humans, is a matter of philosophical discussion. Many philosophers argue that it is in principle beyond the reach of science to prove qualitative phenomenon of the kind related to subjective experiences in other species (e.g. Nagel 1974, Jackson 1986). Regardless of this, science can provide the basis for judging the likelihood of properties such as sentience and consciousness in other species. Ethologists produce 3 types of 'evidence' to prove consciousness. These include attention and perception, episodic memory (the re- collection of events), and the presence of a theory of mind (knowing that others feel or know) (B. Forkman pers. comm.).

Although there may not necessarily be a link between elevated cognitive capacity and the likelihood of pain perception, it has been argued that sophisticated cognitive and behavioural processes add to the likelihood of the conscious experience of suffering (Huntingford et al. 2006). Fish show complex behaviours indicative of advanced cognitive skills (e.g. Chandroo et al. 2004b, Braithwaite 2006). Fish as a taxon have found solutions to almost all the problems that supposedly led to the evolution of a large neocortex and cognitive skills in primates. Several of these skills may even be found in single species: the cleaner fish (found in a variety of fish families) provides an interesting example. It has well-developed spatial memory and social intelligence, advanced cognitive maps, memory and learning, indications of episodic memory and perhaps a theory of mind (Bshary et al. 2002). This may be compared to the skills displayed by birds. In spite of lacking a neocortex, bird species such as parrots, crows and ravens can match primate memory, planning, problem solving, tool use, and social interaction (Pepperberg 1999, Hunt \& Gray 2003, Emery \& Clayton 2004, Pepperberg \& Gordon 2005).

Fish display behaviours indicating pain in situations that would be painful for mammals and this behaviour is similarly reduced when analgesics are given (e.g. Sneddon 2003, Sneddon et al. 2003b). Obviously, some behavioural reactions to nociceptive stimuli are reflexive, like the retraction of a hand from a hot item. While reflexive reactions are functional by limiting damage in acute situations, the conscious experience is important for the learning process, not only by minimizing future risk by teaching the animal to be more careful next time, but by allowing it to benefit from previous experiences by modifying behaviour in new circumstances. It has been shown that fish learn to avoid aversive situations in ways that cannot be explained as simple reflexes (Beukema 1970, Yue et al. 2004, Dunlop et al. 2006).

Some authors claim that a higher order consciousness, an awareness of 'self', is required to consciously experience pain. Self-awareness refers to the capacity of second-order representation of a mental state, i.e. 'thought about thought'. Following this view, it is dubious whether animals other than primates can feel pain (Rose 2002). In humans, self-awareness evolves gradually in early childhood. Still, few will argue that an infant does not feel pain. The ability to feel acute pain likely fulfils a purpose, motivating the individual to avoid injury, thus increasing fitness (chance of survival and reproductive success). Therefore, this ability is likely conserved through evolution and not limited to 
species high in the phylogenetic hierarchy. Griffin (1992) even argues that consciousness may be the most effective way to deal with complex sensory inputs (especially if the brain size is small), compared to having a fixed stimulus response reaction to every situation an animal encounters in its daily life.

To conclude: Physiological evidence together with many indications of sophisticated cognitive behavioural processes in fish substantiate the likelihood that nociceptive stimuli are consciously perceived by fish. The overall picture emerging from research is that at least some fish species can feel pain. Giving the fish the benefit of the doubt, then, they should be morally considered.

\section{FISH ARE NOT TRADITIONALLY INCLUDED IN THE MORAL CIRCLE}

The reasons why fish have so far rarely been included in the moral circle (and their welfare thereby disregarded) may be found in history and tradition, as a result of the difficulty of communicating across species boundaries (i.e. between humans and fish), as well as in our lack of knowledge regarding the capacities of fish. This absence of concern, compared to terrestrial animals, is particularly obvious in countries where animal welfare traditionally has a strong position, such as the Scandinavian countries.

Commercial fisheries may be considered rooted in ancient traditions of hunting. Typically, these practices do not incorporate particular animal care or husbandry elements. Fishermen were among the first salmon farmers, bringing their hunting experience and attendant values and attitudes to fish to the recent profession of fish farming. Also, people with a business background or interest, rather than a desire to work with animals and biosystems, were involved in the first fish farming endeavours (Håstein 2004). Thus, the approach may have been different from that of 'ordinary' farmers who kept and cared for terrestrial animals by looking after the health, well-being and production of their animals from birth to slaughter. The development of fish farming into big business run by multi-national corporations which owe duties to shareholders, distant from the actual production process, has enhanced the view of fish as a 'crop' to be harvested rather than individual animals to be cared for.

In terms of phenomenological experience between humans and animals, the difficulties of communicating with species very different from our own have likely had profound effects on human attitudes and actions towards fish. It is simply difficult for us to imagine what it is like to be a fish. Communication between fish and humans is thwarted since we live in different elements.
The impediments for human-fish contact posed by the water surface also restrict human knowledge about fish biology (see Lien in press), and fish have senses which we lack. Furthermore, fish have an unfamiliar body language and do not possess physical and social characteristics eliciting human empathy in the way most mammals do (Tinbergen 1988); this is often described as the 'Bambi effect'. Fish have no endearing facial features or expressions which we understand spontaneously, and they do not scream or make sounds perceivable to humans which could elicit an empathetic response. In addition, the huge number of fish kept on an average fish farm makes it difficult to consider any one fish, or even to view them in terms of individual animals. Thus, unlike the human relation to farmed terrestrial species, animal welfare concerns towards fishes are scarcely enhanced by human empathy caused by identifiable similarities among species and facilitated by recognition of emotions in individual animals.

The exclusion of fish from the moral circle may not simply be a function of tradition and our inability to identify with them on a physical or phenomenological level. Another reason may be related to an apparent conceptual distance between fish and animal categories ranked 'higher' on the phylogenetic map. According to a common understanding of evolution, fish tend to be perceived as 'lower' vertebrates and, as a consequence of this, it is not hard to imagine that they would also be characterized as 'inferior' and nonsentient, in contrast to the more advanced 'higher' vertebrates, such as mammals.

\section{FISH ETHICS}

In line with the majority of the ethical theories presented above that acknowledge animals' entrance into the moral circle, we argue that if fishes are sentient, this implies that humans should consider their welfare. What this means in practice and how the interests of the involved parties should be weighted against each other are the next questions to be dealt with. Basically, however, one may conclude that the simple line of thought 'Sentient beings should have direct moral concern. Fish are likely to be sentient' will have farreaching consequences if accepted, primarily for the aquaculture industry (given that we have special obligations to farmed animals), but ultimately also for the fisheries.

If one accepts that sentient beings should be morally considered, the basic question which arises is, of course, a scientific one: Are fish sentient? However, the scientific debate around this issue makes it obvious that current science cannot give an unambiguous 
answer. Thus, the immediate question facing us is ethical: How probable does sentience have to be before we feel obliged to act? This question is not unique to fish farming, but part of a perpetual dilemma of policy making - climatic changes and food safety are other examples. Shifting moral responsibility over to scientists (i.e. expecting scientists to give undisputable answers to ethical questions) has a long history. The idea that policy judgements can be based on uniquely reliable knowledge dates back at least to Plato (Millstone 2006). However, a wider understanding of the complexity of policymaking is emerging, acknowledging the ethical dimensions of scientific questions (see for example Tannenbaum 1991, Sandøe \& Simonsen 1992, Millstone 2006). It is important to note that acknowledging the ethical dimension does not make the scientific aspect unimportant. Sound ethics is always based on sound science, and the better the scientific knowledge the more solid the ethical decision.

Regarding the question of the required 'likelihood' of fish sentience, we suggest applying a scientific risk analysis as a first step. In a risk analysis, the estimation of risk is usually based on the expected value of the conditional probability of the event occurring times the consequence of the event, given that it has occurred (Society for Risk Analysis; www.sra.org/resources_ glossary_p-r.php). The 'event' occurring in this case is that fish have the ability to suffer (and thereby qualify as moral objects). The scientific results indicate that there is a non-zero probability that fish are sentient. The consequence, given this ability is present, is the suffering of an enormous number of individual fishes (and also that we, as morally responsible humans, are acting unrighteously, according to the ethical reasoning above). The risk could therefore be large, even though the probability may be low. Therefore, a reasonable risk management strategy would be to implement animal welfare considerations in fish farming even though there is still scientific uncertainty regarding means of measuring fish capacities.

The ethical aspect here involves the estimation of probability and the level of risk that can be accepted, as well as the individual's understanding of human responsibilities towards animals-more precisely, to what degree one is ready to diminish human interests in favour of those of other sentient beings. Thus, a reason why it may be difficult to implement fish welfare may be that, unlike in the case of climatic changes, negative consequences of human neglect in terms of fish welfare considerations willprimarily affect fish and not humans. Consequences may not be considered great (for humans) and therefore the risk is considered low or even negligible, making it easier to disregard the problem - altruism poses a moral challenge. However, implementing fish welfare in aquaculture would probably not be truly altruistic in the present situation. There is likely a win-win situation: basic improvements in fish welfare will in many cases result in an improved economic outcome for the fish farmer.

\section{WELFARE MANAGEMENT OF FISH}

If the conclusion is that fish are morally relevant, it is imperative to know what the concept of welfare for fish actually involves. This question is central for public policy makers and legislators. Standards and legislation must be explicit regarding how fishes should be handled, and it must be possible to control and check up on these regulations, that is, suitable welfare indicators must be identified.

Science, of course, plays a central role in the attempt to answer this question. However, how to understand the concept of welfare is also a question of underlying values, and as such of ethics. The concept of animal welfare is commonly defined in terms of either (1) biological functioning, (2) the affective state of the animal or (3) the importance of a natural life (Duncan \& Fraser 1997). The choice of concept determines the choice of welfare parameters to be used, and eventually, the overall conclusions about the welfare of the animal. Although the definitions overlap to a large extent and, thus, are not exclusive, when welfare indicators point in different directions, the final judgement may depend on the underlying definition chosen (Fraser 2003).

The biological functioning view states that welfare is good when the animal's biological coping systems are not overloaded, i.e. it is healthy, grows, and reproduces normally. Welfare status can thus be relatively easily assessed using health data and physiological parameters such as stress hormones and production data.

The affective state view postulates that what counts is the animal's subjective experience of its situation. However, emotions of other species are not easily assessed, particularly not in species very different from humans. Current knowledge on how measurable parameters correlate to any fish emotions is practically nonexistent. Nevertheless, this view may be what best corresponds to most people's 'gut feelings' about what animal welfare is.

The natural life view is based on the fact that a species has evolved in interplay with a certain ecological niche, causing the need for certain behaviours and feedbacks from its environment. This may give indications of what a good fish life entails for a particular species. For example, due to its 'salmon nature', a farmed salmon may have the behavioural need to migrate, even though it is allowed to swim around and is given sufficient feed in the cage. Bright coloured or illumi- 
nated tanks can be expected to induce stress in species adapted to dark surroundings. Studies of farmed species in natural or semi-natural environments describe their behavioural repertoire, preferences and time budgets. This helps us interpret, for example, whether an inactive halibut is showing contentedness or if it is apathetic.

More important than choosing the 'right' approach is to be explicit about the definition of welfare used. Currently, while many parameters indicating biological functioning are comparatively accessible, knowledge of the natural life and motivations of farmed fish species is limited, as is knowledge of mental states in fish. Scientific research is necessary to develop welfare indicators reflecting these approaches, as well as to provide a better understanding of fish welfare in general and of welfare as related to specific farmed species. Equally important, research is needed to expand on the ethics involved, for example, to set the limits for what is acceptable welfare under different circumstances.

\section{THE WAY FORWARD}

As we see it, the way forward consists of several steps, which include education, research and development, accountability and transparency on the part of the fish farming industry, development, compliance with and control of policies and codes, and quality assurance schemes for consumers. As it is beyond the scope of this paper to discuss all these aspects in detail, we will make but a few remarks.

The first, and the most important as well as the most difficult step, involves education. A kind of mental shift is necessary among consumers and producers alike if they are to be convinced that farmed fish should be included in the moral circle. Education about the nature and capacities of fish should be promoted. Secondly, fish welfare standards need to be developed, and compliance to these standards must be enforced by regulatory bodies. Fish farmers and the fish farming industry must adopt and adhere to a professional attitude of husbandry and care, paying attention to the welfare of the individual fish and resolving the difficulties that this may offer. For all of this to happen, more information, but also more research, is needed to better understand what fish sentience should entail, both in terms of biology and production as well as ethics. In summary, the following need to be developed:

- Information and education, to producers as well as consumers

- Scientific research to better understand what fish welfare means and how it can be implemented in practical fish farming
- Indicators and indices to qualitatively and quantitatively measure fish health and welfare

- Regulations and standards for aquatic production to be used on-farm, by the industry as a whole, as well as on national and international levels

- Health and welfare surveillance systems in aquaculture, both to prevent problems and to enforce the regulations as well as to inform consumers

- Models for fish ethics

When setting welfare standards, it is important to understand basic behavioural mechanisms (Damsgaard et al. 2006). However, the need for research and development does not mean that work to improve fish welfare in aquaculture has to wait for the gaps to be filled in. Measures to improve welfare should be taken based on existing knowledge, scientific as well as empirical. The authorities need to point out the way forward by establishing regulations in a broad risk assessment process involving both ethical and scientific aspects. As mentioned in the 'Introduction', the work of setting standards has already started at an international level. Over the next few years, the industry needs to work out plans for improving fish welfare with realistic goals and timeframes. National programmes for health and welfare surveillance are necessary to support this work, and to detect emerging problems. In addition, the kind of balanced debate signifying a democratic society will be necessary to bring fish welfare onto the agenda of the different stakeholders: fish farmers, consumers, the aquaculture industry, national and international authorities.

We note that in order to make progress we need ethics, science and public policy discussions, as well as an informed and interested public and industry. We need ethics to enable us to discuss and discern the criteria that determine inclusion in the moral circle and to define the quality and quantity of welfare, science to validate these criteria, and discussions to formulate welfare guidelines based on ethics and science. Fish welfare deserves serious moral consideration.

Acknowledgements. The authors are sincerely grateful to Dr. David Scarfe, Dr. Bergljot Børresen, Dr. Helga Høgåsen and Prof. Adroaldo Zanella for valuable comments on earlier versions of this article.

\section{LITERATURE CITED}

Aquinas T (1947) Summa theologica, Part 2, Question 64, Article 1, Question 25, Article 3. Benziger Brothers, Chicago, IL (first publ. in ca. 1266-1273)

Bentham J (1966) Introduction to the principles of morals and legislation. Clarendon Press, Oxford (first publ. in 1789)

Bermond B (1997) The myth of animal suffering. In: Dol M, Kasamoentalib S, Lijmbach S, Rivas E, Vandenbos R (eds) 
Animal consciousness and animal ethics: perspectives from the Netherlands. Van Gorcum, Assen, p 125-143

Beukema JJ (1970) Angling experiments with carp (Cyprinus carpio L.) II. Decreasing catchability through one-trial learning. Neth J Zool 20:81-92

Børresen B (in press). Fisk og forskere. Transit Press, Oslo

Braithwaite V (2006) Cognitive ability in fish. Fish Physiol 24:1-37

Broom DM (1998) Welfare, stress, and the evolution of feelings. Adv Stud Behav 27:371-403

Bshary B, Wickler W, Fricke H (2002) Fish cognition: a primate's eye view. Anim Cognition 5:1-13

Chandroo KP, Moccia RD, Duncan IJH (2004a) Can fish suffer? Perspectives on sentience, pain, fear and stress. Appl Anim Behav Sci 86:225-250

Chandroo KP, Yue S, Moccia MD (2004b) An evaluation of current perspectives on consciousness and pain in fish. Fish Fish 5:281-295

Crick F, Koch C (1998) Toward a neurobiological theory of consciousness. Semin Neurosci 2:263-275

Damsgård B, Juell J, Braastad B (2006) Welfare in farmed fish. Fiskeriforskning, Report 5/2006. Also available at: www.fiskeriforskning.no/fiskeriforskning/publikasjoner/ rapporter/welfare_in_farmed_fish

Danbury TC, Weeks CA, Chambers JP, Waterman-Pearson AE, Kestin SC (2000) Self-selection of the analgesic drug carprofen by lame broiler chickens. Vet Rec 146: 307-311

Descartes R (1988) Discourse on method. In: Descartes R (date) Selected philosophical writings. Cambridge University Press, Cambridge (translated by J. Cottingham) (first publ. in 1637)

Divac I, Holst MC, Nelson J, McKenzie JS (1987) Afferents of the frontal cortex in the echidna (Tachyglossus aculeatus). Indication of an outstandingly large prefrontal area. Brain Behav Evol 30:303-320

Duncan IJH, Fraser D (1997) Understanding animal welfare. In: Appleby MC, Hughes BO (eds) Animal welfare. CAB International, Wallingford, p 19-31

Dunlop R, Millsopp S, Laming P (2006). Avoidance learning in goldfish (Carassius auratus) and trout (Onchorynchus mykiss) and implications for pain perception. Appl Anim Behav Sci 97:255-271

Emery N, Clayton N (2004) The mentality of crows: convergent evolution in intelligence in corvids and apes. Science 306:1903-1907

Fraser D (2003) Assessing animal welfare at the farm and group level: the interplay of science and values. Anim Welf 12:433-443

Frey, RG (1980) Interest and rights: the case against animals. Clarendon Press, Oxford

Fuster JM (1980) The prefrontal cortex. Anatomy, physiology, and neuropshychology of the frontal lobe. Raven Press, New York

Gentle MJ (1992) Pain in birds. Anim Welf 1:235-247

Griffin DR (1992) Animal minds. University of Chicago Press, IL

Håstein T (2004) Akvakultur. Fra kultivering til storindustri. Veterinærvesenets rolle i akvakultur nasjonalt og internasjonalt. In: Kvaløy S Sr (ed) Norsk Veterinærhistorisk Selskap Årbok. Selskapet, Oslo, p 27-52

Håstein T, Scarfe D, Lund VL (2005) Science-based assessment of welfare: aquatic animals. Rev Sci Tech Off Int Epiz 24:529-547

Hunt GR, Gray RD (2003) Diversification and cumulative evolution in New Caledonian crow tool manufacture. Proc $\mathrm{R}$ Soc Lond B 270:867-874
Huntingford FA, Adams C, Braithwaite VA, Kadri S, Pottinger TG, Sandøe P, Turnbull, JF (2006) Current issues in fish welfare. Review paper. J Fish Biol 68:332-372

Jackson F (1986) What Mary didn't know. J Philos 83:291-295

Kalish R, Wiech K, Critchley HD, Dolan RJ (2006) Levels of appraisal: a medial prefrontal role in high-level appraisal of emotional material. Neuroimage 30:1458-1466

Kant I (1980) Lectures on ethics. Hackett Publishing Company, Indianapolis, IN (translated by L. Infield) (first publ. in 1888)

Larrère C, Larrère R (2000) Animal rearing as a contract? J Agric Environ Ethics 12:51-58

Lieberman P (2006) The neural basis of language. In: Toward an evolutionary biology of language. Harvard University Press, Cambridge, MA

Lien ME (in press) Domestication 'downunder': Atlantic salmon farming in Tasmania. In: Cassidy R, Mullin M (eds) Where the wild things are now; domestication reconsidered. Berg, Oxford

Lund V, Olsson A (2006) Animal agriculture: symbiosis, culture or ethical conflict? J Agric Environ Ethics 19:47-56

Lund V, Anthony R, Röcklinsberg H (2004) The ethical contract as a tool in organic animal husbandry. J Agric Environ Ethics 17:23-49

Midgley M (1983) Animals and why they matter. University of Georgia Press, Athens, GA

Millstone E (2006) Can food safety policy-making be both scientifically and democratically legitimated? If so, how? In: Kaiser M, Lien M (eds) Ethics and the politics of food. Preprints 6th EurSAFE Congress, Wageningen Academic Publishers, Wageningen, p 36-47

Mogensen J, Divac I (1982) The prefrontal 'cortex' in the pigeon. Behavioral evidence. Brain Behav Evol 21:60-66

Nagel T (1974) What is it like to be a bat? Phil Rev 83:435-450

Pepperberg IM (1999) The Alex studies, cognitive and communicative abilities of grey parrots (Psittacus eritiacus). Am Zool 40:893-901

Pepperberg IM, Gordon JD (2005) Number comprehension by a grey parrot (Psittacus erithacus), including a zero-like concept. J Comp Psychol 119:197-209

Regan T (1983) The case for animal rights. University of California Press, Berkeley

Röcklinsberg H (2001) Das seufzende Schwein. Zur Theorie und Praxis in deutschen Modellen zur Tierethik. Harald Fischer Verlag, Erlangen

Rollin B (1995) Farm animal welfare. Iowa State University Press, Ames, IA

Rose JD (2002) The neurobehavioral nature of fishes and the question of awareness and pain. Rev Fish Sci 10:1-38

Rollin BE (1995) Farm animal welfare. Iowa State University Press, Ames, IA

Sandøe P, Simonsen HB (1992) Assessing animal welfare: Where does science end and philosophy begin? Anim Welf 1:257-267

Singer P (1981) The expanding circle: ethics and sociobiology. Farrar, Straus \& Giroux, New York

Singer P (1990) Animal liberation, 2nd edn. New York Review of Books, New York

Sneddon LU (2002) Anatomical and electrophysiological analysis of the trigeminal nerve in teleost fish, Oncorhyncus mykiss. Neurosci Lett 319:167-171

Sneddon LU (2003) The evidence for pain in fish: the use of morphine as an analgesic. Appl Anim Behav Sci 83:153-62

Sneddon LU, Braithwaite VA, Gentle MJ (2003a) Do fishes have nociceptors? Evidence for the evolution of a vertebrate sensory system. Proc R Soc Lond B Biol Sci 270: $1115-21$ 
Sneddon LU, Braithwaite VA, Gentle MJ (2003b) Novel object test: examining nociception and fear in the rainbow trout. J Pain 4:431-440

Sohlberg S, Mejdell C, Ranheim B, Søli NE (2004) Oppfatter fisk smerte, frykt og ubehag? - en litteraturgjennomgang. Nor Veterinærtidsskr 116:429-438

Sundli A (1999) Holmenkollen guidelines for sustainable aquaculture (adopted 1998). In: Svennevig N, Reinertsen $\mathrm{H}$, New M (eds) Sustainable aquaculture: food for the future? Proc 2nd Int Symp on Sustainable Aquaculture, Oslo, Norway, 2-5 November 1997. A. A. Balkema, Rotterdam, p 343-347

Tannenbaum J (1991) Ethics and animal welfare: the inextri-

Editorial responsibility: Anne Berit Skiftesvik, Storebø, Norway cable connection. JAVMA (J Am Vet Med Assoc) 198: $1360-1376$

The Avian Brain Nomenclature Consortium (2005) Avian brains and a new understanding of vertebrates brain evolution. Nat Rev Neurosci 6:151-159

Tinbergen N (1988) The study of instinct, 2nd edn. Clarendon Press, Oxford

Wolf U (1990) Das Tier in der Moral. Klostermann, Frankfurt am Main

Yue S, Moccia RD, Duncan IJH (2004) Investigating fear in domestic rainbow trout, Oncorhynchus mykiss, using an avoidance learning task. Appl Anim Behav Sci 87: $343-354$

Submitted: August 28, 2006; Accepted: February 21, 2007 Proofs received from author(s): April 25, 2007 